\title{
Titulación de la propiedad y mercado inmobiliario*
}

\author{
Julio Calderón Cockburn**
}

En este estudio se analiza la relación entre la tenencia de títulos de propiedad (registrados) y los mercados inmobiliarios en aquellas zonas de la ciudad cuyo origen fue informal o ilegal. Al hacerlo se plantean cuestionamientos a los presupuestos internacionales y se encuentran paradojas en el funcionamiento del mercado de suelo popular. La metodología es cuantitativa y cualitativa. Las conclusiones muestran que en los asentamientos no consolidados la tenencia de un título de propiedad contribuye a conferir un mayor valor a los predios en relación con los que no están titulados. No obstante, el título de propiedad no necesariamente induce al predominio de los mercados inmobiliarios formales; más bien se mantienen las tendencias que apuntan a las transacciones informales en cuanto a alquileres, compras y ventas.

Palabras clave: mercado inmobiliario, títulos de propiedad, formalidad, precio de suelo, vivienda consolidada, vivienda en consolidación.

Fecha de recepción: 30 de noviembre de 2009.

Fecha de aceptación: 6 de abril de 2010.

\section{Property Deeds and Real Estate Market}

This study analyzes the link between the ownership of property deeds (registered) and real estate markets in parts of the city whose origin was either informal or illegal. By doing so, it raises questions about international assumptions and finds paradoxes in the way the popular land market operates. The methodology used is both quantitative and qualitative. The conclusions show that in unconsolidated settlements, ownership of title deeds increases property value. Title deeds do not however, increase the predominance of formal property markets. On the contrary, the tendency to engage in informal transactions regarding rent and buying and selling continues to exist.

* La doctora Dina Li atendió los aspectos de análisis estadístico y definición de la muestra de la encuesta. El arquitecto Julio Delgado fue asistente del estudio. Jesús Quispe, Teresa Arias y Alberto Amanzo aplicaron encuestas y entrevistas grabadas en las zonas seleccionadas. Tania Huamán, Dilma Eulogio, Celinda Eulogio y Carmen Noriega participaron en las encuestas. Martim Smolka, Ciro Biderman y María Teresa Souza aportaron con sus comentarios. El Lincoln Institute of Land Policy apoyó en la financiación del trabajo de campo. El autor agradece sus valiosas contribuciones y asume la responsabilidad por cualquier deficiencia que pueda tener el artículo.

** Profesor de la Facultad de Ciencias Sociales de la Universidad Católica del Perú y de la Facultad de Arquitectura y Urbanismo de la Universidad Nacional de Ingeniería (UNI); profesor asociado del Programa de América Latina y el Caribe del Lincoln Institute of Land Policy de Estados Unidos. Correo electrónico: calderon@chavin.rcp.net.pe. 
Key words: real estate market, title deeds, formality, land prices, consolidated housing, housing undergoing consolidation.

\section{Introducción}

Naturaleza, alcance y preguntas del estudio

Las políticas de titulación en los asentamientos ilegales e informales de las ciudades de América Latina han venido cambiando la realidad social urbana sobre la que actúan. Estas políticas responden a los esfuerzos por reducir la informalidad en las ciudades. Se ha supuesto en el mundo entero que los títulos posibilitarán el acceso al crédito formal de la banca, elevarán el valor de las propiedades e incentivarán un mercado inmobiliario formal. Los títulos de propiedad contribuirán asimismo a alcanzar la formalidad en las ciudades.

El propósito de este estudio es observar el efecto de la tenencia de títulos de propiedad registrados en los mercados inmobiliarios locales. ${ }^{1}$ Para ello se examinan tanto los asentamientos viejos como los nuevos de la ciudad de Lima que en sus orígenes fueron ilegales e informales. Cabe plantear algunas preguntas específicas en torno a la titulación y los mercados inmobiliarios en el espacio local: ¿El título de propiedad incentiva realmente los mercados inmobiliarios formales?, ¿eleva el valor del suelo?

El análisis de sus aspectos institucionales y políticos se centrará en un espacio local con población salida de la pobreza y pobre todavía, la cual constituye un enorme caudal electoral de interés para las elites. Asimismo se tomará en cuenta que en Perú se aplica una política de formalización, que entre 1996 y 2007 entregó más de 1.6 millones de títulos, la mayoría en el año 2000. Por último se examina una política de formalización de la propiedad que suele citarse como exitoso caso de reducción masiva de la pobreza mundial (Banco Mundial), y que ha puesto el énfasis en el fortalecimiento y uso de los derechos de propiedad de los beneficiarios. ${ }^{2}$

${ }^{1}$ No se abordan temas como la relación de los títulos con las inversiones en vivienda, el acceso al crédito o a hipotecas, la generación de empleo, ingresos, movilidad laboral o el incremento de recaudación tributaria.

${ }^{2}$ La formalización de la propiedad, según sus impulsores, iría más allá de dar títulos, y se propondría generar un entorno de derechos de propiedad que integrara a la población antes informal mediante la eliminación de los abismos que median entre la población que tiene títulos y la que no los tiene (Varela, 2008). 


\section{Estado de la cuestión}

Son muy pocos los estudios sobre los mercados inmobiliarios en las zonas "urbanas marginales" de América Latina. Incluso se ha soslayado la temática para concentrarse en atender la autoconstrucción de la vivienda. Sólo se conocen generalidades sobre el mercado inmobiliario en los asentamientos, es poco lo que se sabe acerca de las relaciones que establecen los actores y los agentes económicos, y aún menos sobre las expresiones sociales que exponen y que podrían resultar enigmáticas en su superficie. Ese poco conocimiento contrasta con la actual preocupación por intervenir en dichas zonas de la ciudad.

Se suele acusar a los mercados inmobiliarios en asentamientos ilegales de que generan consecuencias excluyentes y segregadoras, desplazamientos y sucesiones en perjuicio de los pobres. Según algunos estudiosos el mercado inmobiliario (commodification) emerge ya en las etapas de consolidación (Ramírez, Harms y Mathey, 1992; Gilbert, 2001). Conforme a otras perspectivas, la dinámica en que operan los mercados de tierras bajo la regularización no parece encaminarse a una solución de la informalidad urbana (Smolka, 2003).

Prácticamente no hay estudios sobre el efecto del título en los mercados inmobiliarios, aunque sí aproximaciones que forman parte de una discusión más general. En el mundo no son muchos los estudios que se enfocan en el análisis y la cuantificación de tales efectos; sólo hay algunos muy rudimentarios y para pocas naciones (Baharoglu, 2002). No obstante, tras revisarlos se advierten ciertos consensos y debates al respecto.

Hay consenso en que los títulos incrementan el valor de la propiedad. En Perú se ha estimado que el efecto marginal de un título de propiedad en cada pieza es un incremento de 925 dólares de Estados Unidos (Apoyo Consultoría, 2003). En Ecuador se estima que el título aumenta el valor de las propiedades en $23.5 \%$, y en Yakarta un lote titulado tiene un premio en el proceso de venta de $45 \%$ sobre otro no titulado. La evidencia mundial sugiere que el precio se incrementa en 25\% gracias al título (Payne et al., 2007: 15).

No obstante hay discrepancias acerca de quién es el beneficiario del incremento del valor que otorga el título de propiedad. Algunos aseguran que es una buena noticia para los que están vendiendo pero no para los que están comprando, e incluso para los que venden puede tener un rebote en el precio de otras zonas de la ciudad hacia donde pretenden desplazarse, y esto reduce parcialmente los beneficios que obtuvieron inicialmente. 
La conocida y difundida obra de Hernando de Soto $(1986,2000)$, se ha basado en la nueva economía institucional y con ello ha creado nuevos puntos polémicos en torno a la propiedad, los mercados inmobiliarios y la economía en general. Es un particular tema de debate, pues según De Soto (2000) los bienes no escriturados en un sistema formal de propiedad difícilmente pueden moverse en el mercado, y si lo hacen es en un círculo muy restringido. Gilbert (2001), por el contrario, asegura que en América Latina las tierras y viviendas se venden aun sin título, que las viviendas se alquilan en el mercado antes de que lleguen los títulos, y que la ilegalidad de la transacción sólo reduce el precio, pero no anula el mercado. Asimismo se debate sobre si los títulos favorecen o no los procesos de movilidad residencial (Gilbert, 2001). ${ }^{3}$

En cuanto al nexo entre los títulos de propiedad y el acceso al crédito, en Perú se ha demostrado que no hay relación entre ellos (Apoyo Consultoría, 2000 y 2003; Calderón 2001, 2002, 2003 y 2007a; Field y Torero, 2004; Caria, 2008). Incluso, a veces, la población sin título puede acceder a más créditos. El entusiasmo del Banco Mundial al respecto se ha matizado (Payne et al., 2007); no obstante, en la escena internacional prima la idea de que los títulos facilitan el acceso a los créditos.

\section{La formalización de la propiedad}

Hace más de dos décadas se difundió un discurso a favor de la formalización de la propiedad. De Soto $(1986,2000)$ ha insistido en que la vivienda informal es un bien que, por no estar dentro de un sistema formal de propiedad, difícilmente se negocia en el mercado y sólo puede venderse en un círculo restringido, dado que el comprador abriga dudas sobre la titularidad del derecho y traslada el riesgo como un costo al vendedor. La falta de derechos de propiedad establecidos dificulta su inserción en el mercado inmobiliario. ${ }^{4}$ Sobre esta propues-

${ }^{3}$ Gilbert encontró en un asentamiento en Bogotá que en un año sólo 4 de 276 propietarios se habían movido, esto es, $1.4 \%$. Similares situaciones suelen presentarse en Caracas y México.

${ }^{4}$ De acuerdo con la Nueva Economía Institucional el derecho de propiedad es la libertad de elegir o la capacidad de adoptar una decisión referente a un bien o servicio. Los costos de transacción son los de transferir derechos de propiedad y de establecer y mantener dichos derechos. Coase sostiene que la adecuada definición de derechos de propiedad privados permite internalizar las externalidades que surgen bajo un sistema donde los bienes son de acceso general o libre, es decir, donde ninguna persona puede estar excluida del derecho a usar el bien en cuestión (Aldana y Fort, 2001). El teorema 
ta cabe mencionar que en el mundo ha cobrado fuerza la idea de que la distribución de títulos de propiedad como parte de una reforma institucional incentivará un comportamiento proclive a la formalidad en los actores económicos.

En la bibliografía vinculada al Proyecto Derechos de Propiedad Urbana (PDPU), 1998-2004, se advierten algunos nexos entre los títulos de propiedad y los mercados inmobiliarios. Apoyo Consultoría (2000), tras elaborar la Encuesta de Línea de Base del PDPU-Cofopri (Comisión de Formalización de la Propiedad Informal), consideró que la formalización acarrearía cuatro tipos de beneficios: social, económico, interacción social y recaudación fiscal. Entre los económicos mencionó el incremento del mercado laboral y de los ingresos, el aumento del potencial económico del predio, el acceso a crédito, la mejoría de la capacidad de consumo y ahorro, y un mercado inmobiliario formal (Apoyo Consultoría, 2000: 27).

La política de formalización espera tres beneficios del nexo de titulación y los mercados inmobiliarios, considerando las transacciones de compraventa y de alquiler: ${ }^{5}$

1) Lograr que la propiedad sea definible, defendible y enajenable.

definible supone que existan en la ley mecanismos para reconocerlos como derechos exclusivos, oponibles y legítimos [...] defendibles implica la posibilidad legal de que sus titulares empleen la coerción estatal para defenderlos [...] enajenables significa que sus titulares puedan legalmente disponer de todo o parte de sus derechos, de diferentes maneras, con bajos costos de transacción y a través del derecho a contratar libremente [Mosqueira, 2000: 107].

\footnotetext{
de Coase dice "si no existieran los costes de transacción, la asignación de recursos sería siempre la más eficaz, cualquiera que fuese la distribución de derechos de propiedad". La estructura de los derechos de propiedad determina quién se apropia de los beneficios y asume los costos de llevar adelante actividades económicas, definiendo a los actores en el proceso económico y estructurando el sistema de incentivos (Barrantes y Trivelli, 1994).

${ }^{5} \mathrm{El}$ profesor Ciro Biderman, con base en una teoría del riesgo, sostiene que deben esperarse efectos del título en el mercado de compraventa pero no en el de alquiler (comunicación personal). En cambio los propulsores de la formalización sostienen que la seguridad jurídica del predio disminuirá los costos de transacción, aumentará las oportunidades del intercambio formal de activos e incrementará el valor de la propiedad, y concluyen que "se esperaría que el título de propiedad de Cofopri alivie las restricciones a la compra, venta y alquiler de viviendas o locales comerciales y aumente las transacciones financieras en el mercado" (Morris, 2005: 115).
} 
2) Integrar la propiedad a los mercados inmobiliarios formales.

- La formalización favorecerá:

la integración social y económica de los pobladores de escasos recursos económicos, reconociendo el ahorro y la inversión realizados en los predios que ocupan, y revalorizando sus propiedades a través de la titulación de sus predios [...] la formalización [...] busca convertir en activos líquidos la propiedad predial de los sectores informales de menores recursos, para integrarlos en el mercado inmobiliario y que sean objeto de transacciones [Mosqueira, 2000: 127].

- El Programa de Derechos de Propiedad Urbana de Perú (PDPU) consideró que de un uso más eficiente de la propiedad por la seguridad obtenida, se desprendería un beneficio económico para las familias. Ese uso incrementaría el valor del predio, otorgaría a sus propietarios la posibilidad de realizar mayores transacciones en el mercado inmobiliario y la de usar la propiedad como garantía para obtener créditos. Al disminuirse los costos de transacción se aumentaría la oportunidad de realizar un intercambio formal de activos. El resultado sería una reducción de la dependencia del mercado informal, y una tendencia hacia la formación de un mercado inmobiliario reconocido (Morris, 2005: 103 y 115).

- Apoyo Consultoría (2000) presenta una secuencia al respecto: El título facilita intercambio de activos en el mercado formal $\rightarrow$ reduce la dependencia al mercado informal $\rightarrow$ aumenta las oportunidades de transacción (algo vinculado al aumento del valor de la propiedad por inversión individual y colectiva) $\rightarrow$ aumenta el volumen de transacciones de lotes $\rightarrow$ impulsa el desarrollo del mercado inmobiliario formal en la zona.

3) La reducción a la larga de los precios de los inmuebles. Apoyo Consultoría (2000) se opone a las eventuales consecuencias negativas y excluyentes, y sostiene que a la larga el desarrollo de los mercados inmobiliarios formales beneficiará a la población en general. Argumenta que ante la ausencia de registro de la propiedad existen precios e impuestos diferenciados para una tierra titulada y una no titulada. Cuando todos los predios se titulan aumenta la oferta de tierras tituladas y por tanto su precio tiende a disminuir. Así, "al mismo tiempo, la demanda por tierras que habían sido no tituladas tiende a aumentar, la titulación remueve el impuesto. El resultado neto 
es el incremento del precio de un predio no titulado y la caída del predio titulado" (Apoyo Consultoría, 2000: 75). Como consecuencia los dueños de las tierras tituladas verían reducir el precio de éstas, con una pérdida neta para ellos pero no para la sociedad (Apoyo Consultoría, 2000: 76).

\section{Enfoque del estudio}

Se asume que las personas pobres o salidas de la pobreza que habitan en los asentamientos populares de la ciudad, buscan su mejoría y su bienestar en la reproducción social. Con ese propósito ponen en juego todos los recursos sociales y económicos de los que disponen, incluyendo la propiedad de su tierra y su vivienda. El uso de la propiedad predial (su compra, venta, alquiler, reserva como tierra baldía o vivienda) dependerá de ciertas prácticas razonables en que el actor pondrá en juego un conjunto de disposiciones. ${ }^{6}$

El mercado inmobiliario, como todo mercado, es un espacio de coordinación de agentes, un proceso social y económico en demanda de seguridad, localización, movilidad social, diferenciación social, objetivación de gustos, estatus, establecimiento o reforzamiento de diferencias y distinciones. En la oferta operan criterios de rentabilidad y de recurso al patrimonio. La sociología urbana suele considerar al mercado inmobiliario como un medio de diferenciación de los grupos sociales y de las actividades económicas en el espacio (usos del suelo). ${ }^{7}$

Se considera que la propiedad inmobiliaria, en tanto tal si es reconocida jurídicamente por el Estado, es un capital económico con el que cuentan las personas o las familias. Este capital se expresa en un capital simbólico en la medida en que implica el reconocimiento de la sociedad al asociarlo a la respetabilidad, la seguridad, la estabilidad

6 "La ortodoxia económica pasa por alto el hecho de que las prácticas pueden tener principios distintos de las causas mecánicas o la intención consciente de maximizar las propias utilidades y aún así obedecer a una lógica económica inmanente. Las prácticas conforman una economía, esto es, siguen una razón inmanente que no puede restringirse a la razón económica, pues la economía de las prácticas puede ser definida en referencia a un amplio espectro de funciones y finalidades" (Bourdieu, 2005: 179).

${ }^{7}$ Para la Escuela de Chicago esta diferenciación (segregación) era un producto natural de la competencia entre los individuos, y la mano invisible del mercado definía el predominio de las personas de mayores ingresos, quienes alcanzaban los mejores lugares de la ciudad. Para la Nueva Sociología Urbana el mercado inmobiliario condensa y expresa fenómenos como la segregación urbana, el refugio y aislamiento de las elites y el desplazamiento de los más débiles y pobres hacia los peores terrenos. 
emocional, la confianza y el estatus que brinda el saber que no serán desalojados. Es un fenómeno que captan bien las expresiones "ser dueño", o "ser propietario".

En tanto parte del patrimonio familiar, la propiedad inmobiliaria influye en los mecanismos de reproducción social en cuanto se le usa, y también en los mercados de tierras y viviendas bajo mecanismos institucionalizados (legales) o no. En contraposición a cierto consenso internacional en los círculos oficiales o afines, sostengo que no debe deducirse de la tenencia de un título de propiedad que los actores insertarán sus actos subsecuentes, tales como las transacciones inmobiliarias, en la formalidad. Las prácticas de los actores en el mundo social resultan más complejas que las previstas por un razonamiento simple que deduce de las modificaciones institucionales una serie de comportamientos económicos orientados por la legalidad.

Si bien es cierto que la tenencia de una propiedad registrada del suelo y de la vivienda sienta una base para un comportamiento orientado a la formalidad, no debe inferirse de ello que en adelante los actores se desempeñarán con sujeción a las leyes que rigen a la sociedad, dado que, siguiendo a Max Weber, los agentes obedecen la ley en la medida en que su interés por seguirla supere su interés por ignorarla (Bourdieu, 2005).

En la inserción de las familias a los sistemas de estrategias de reproducción social, el uso y recurso, formal o informal, de la propiedad inmobiliaria dependerá de los beneficios diferenciales que puedan esperar en función de los poderes efectivos de los que dispongan, los cuales se establecen de acuerdo a su volumen y estructura de capital (incluyendo sus ingresos, empleo, ahorros, prestigio, etc.). Tales poderes dependerán de la inserción de los actores en la estructura de distribución de la sociedad.

De manera que los aprovechamientos de la propiedad inmobiliaria (compra, venta y alquiler) estarán sujetos a los límites y beneficios diferenciales vigentes (tales como la localización del barrio, la característica y dimensión de la vivienda, el estigma social de la zona) que difícilmente podrán modificar los actores en cierto periodo de tiempo. Por otro lado, como se infiere de una discusión hoy casi olvidada, los actores se inclinarán por la informalidad en tanto el costo de actuar en la formalidad sea mayor. Por ejemplo, un arrendador optará por alquilar informalmente si el costo de hacerlo formalmente le implica pagar impuestos y le reduce sus beneficios, más allá de que cuente o no con un título de propiedad. 


\section{Los métodos}

En este estudio comparativo se pretende determinar si el título de propiedad acarrea alguna diferencia en los mercados inmobiliarios que se desarrollan en los asentamientos viejos y ya consolidados, y en los jóvenes aún no consolidados de Lima. Una diferencia en el valor del predio entre las zonas tituladas o no, proporcionará pistas al vincular los valores y precios del mercado de tierras con la tenencia de un título de propiedad. Asimismo se podrán establecer asociaciones entre las zonas tituladas o no y el desarrollo de mercados inmobiliarios formales o no.

Se trata de una investigación social comparativa que se fundamenta en casos, considerados no como un objeto de estudio peculiar en sí, sino como un medio que da la posibilidad de comprender mejor el problema enunciado (Gundermann, 2004), a saber, el nexo entre los títulos y los mercados inmobiliarios.

La selección de los casos ha respondido a la búsqueda del mayor aislamiento posible de la variable a analizar: zonas con títulos de propiedad y sin él. En esa medida para la definición de los casos, tanto en los asentamientos consolidados como en los no consolidados, se estableció una localización espacial similar con relación al tiempo de traslado desde el centro histórico de la ciudad. En la comparación entre los asentamientos consolidados ("viejos") y los no consolidados ("nuevos") se incluye un aspecto temporal que, a su vez, da cuenta de niveles de consolidación que deberían considerarse en las políticas urbanas y sociales que se adoptan en las zonas informales e ilegales de las ciudades del Tercer Mundo.

Los asentamientos consolidados y viejos que se seleccionaron fueron Villa El Salvador Sector I (con título) y Huáscar (con título), y la variable control fue Huáscar (un sector sin título).

El Sector I de Villa El Salvador, en el distrito del mismo nombre, cuenta con aproximadamente 10207 lotes y fue fundado por el sector público en 1971 como zona de reubicación. Sus viviendas se encuentran ya consolidadas y tiene servicios. Inicialmente, en la década de 1980, fue titulada por la Municipalidad de Lima, y el registro de las propiedades fue obra de la Cofopri una década después. Se halla a unos 50 minutos del centro de la ciudad en transporte público. El sector B de Huáscar, en San Juan de Lurigancho, con aproximadamente 1797 lotes, fue fundado por una reubicación del sector público en 1976. Sus viviendas están consolidadas y cuentan con servicios. Fue titulado por 
la Municipalidad de Lima en los ochenta y las propiedades registradas por la Cofopri en los noventa. Está a unos 50 minutos del centro de la ciudad en transporte público. El sector C de Huáscar (caso control), en San Juan de Lurigancho, cuenta con 1412 lotes, y sus pobladores, que comparten una historia común con el Sector B, por un error de los funcionarios gubernamentales fueron asentados en una zona que un tribunal había retornado a los propietarios privados expropiados un año antes (1975). Actualmente existe un juicio entre los propietarios y los pobladores, quienes se resisten a pagar. La Municipalidad de Lima les otorgó títulos de propiedad a fines de la década de 1980, pero la Cofopri no los ha registrado aduciendo que existe un conflicto judicial pendiente. Por lo tanto es un asentamiento no titulado. Se halla a unos 55 minutos del centro histórico de la ciudad en transporte público.

De los asentamientos jóvenes y no consolidados se seleccionó a Ampliaciones Huáscar (con título) y la Zona Alta de Huaycán (sin título). Se procuró que las zonas se parecieran lo más posible para reducir la influencia de la variable independiente (título de propiedad). Ambos asentamientos están a unos 70 minutos del centro histórico de la ciudad.

Ampliaciones Huáscar, con unos 2396 lotes, pertenece al distrito de San Juan de Lurigancho. Se formó por invasión de los cerros hacia 1996 y los pobladores recibieron sus títulos en el año 2000. Cuentan con servicio de luz eléctrica domiciliaria, alumbrado público y agua potable (2005-2007), lo cual influye en la compra y venta de lotes (Calderón, 2007). El caso control es la Zona Alta de Huaycán (1 127 lotes) en el distrito de Ate, que se pobló de 1998 a 2000 como una continuación no planificada del Proyecto Especial Huaycán que desarrolló la Municipalidad de Lima en julio de 1984. Según un autocenso de la población, en 2006 sólo 2\% tenía título de Cofopri, 38\% tenía título municipal y $60 \%$ no tenía título. El principal escollo para la titulación era levantar las observaciones del Instituto de Defensa Civil respecto a la ubicación de las viviendas en área de riesgo (Villanes, 2006). En la zona hay expectativa por la titulación y la provisión de servicios.

La metodología incluye técnicas de recolección de información cuantitativa y cualitativa.

La encuesta muestral se aplicó en los casos y en los casos control (cuadro 1), previa definición de las manzanas. Los encuestadores cubrieron las zonas seleccionadas y entrevistaron a los pobladores que habían participado en alquileres, compras y ventas durante el último 


\section{CUADRO 1}

\section{Asentamientos considerados, población total y muestra}

\begin{tabular}{lcc}
\hline Casos & Total de lotes & Muestra \\
\hline Consolidado titulado & 10207 & 112 \\
$\quad$ Villa El Salvador Sector I & 1797 & 52 \\
$\quad$ Huáscar B & 1412 & 48 \\
Consolidado sin título & & \\
$\quad$ Caso control Huáscar C & 2396 & 112 \\
No consolidado titulado & & 74 \\
$\quad$ Ampliaciones Huáscar & 1127 & 78 \\
$\quad$ No consolidado sin título & & \\
\hline
\end{tabular}

FUENTE: Elaboración propia.

año (mayo de 2007 a abril de 2008). No se definió un cupo para cada tipo de transacción, sino que se encuestó lo que se encontraba, con lo cual se obtuvo una expresión más cabal del tipo de transacciones que ocurren.

En términos cualitativos, el estudio aplicó diez entrevistas a compradores. Las entrevistas se distribuyen de la siguiente manera: una en Huáscar B consolidado y titulado; una en Huáscar C consolidado y no titulado; una en Ampliaciones Huáscar no consolidado titulado; y siete en Huaycán Zona Alta no consolidado y no titulado.

\section{Los resultados}

La indagación central buscó establecer si los títulos de propiedad en los asentamientos ocasionan diferencias con relación al establecimiento de mercados inmobiliarios formales, según considera la política de formalización, y asimismo, si contribuyen a incrementar los valores de los predios.

En el cuadro 2 se advierte que en los asentamientos consolidados con título predominan como transacciones inmobiliarias los alquileres de viviendas $(86 \%)$, y en aquellos no consolidados con título más bien son los procesos de compra $(65 \%)$ y venta $(25 \%)$. De manera que en asentamientos consolidados y mejor localizados los propietarios de viviendas no están vendiendo, sino más bien alquilando. Estas tenden- 


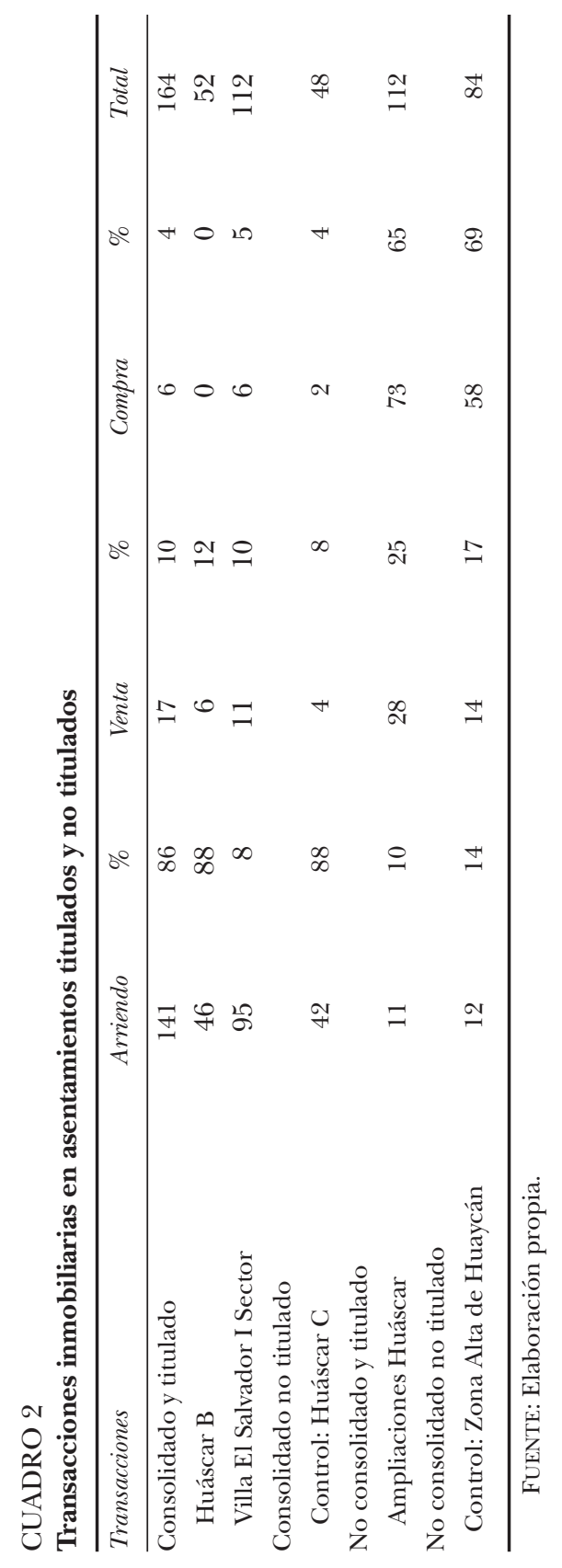


cias se mantienen en los casos control, lo cual, en principio, quiere decir que las variables de localización y urbanización son factores que impulsan los alquileres. En términos del análisis estadístico, el aporte del título al valor de los predios es factible en el caso de los asentamientos no consolidados en que predominan compras y ventas. ${ }^{8}$

\section{Asentamientos consolidados}

En el mercado inmobiliario de los asentamientos consolidados predominan los alquileres. En los que cuentan con título de propiedad Cofopri (Huáscar B, Villa El Salvador I Sector), los alquileres constituyen $86 \%$ y son muy escasas las ventas $(10 \%)$ y las compras $(4 \%) .{ }^{9}$ Este hallazgo es un aporte a los estudios que verifican el predominio de arriendos en las zonas urbano populares consolidadas, como se ha verificado en las ciudades de Bogotá y Caracas (Parias, 2006; Briceño León, 2006). Esta tendencia tendría que ver con la localización de los asentamientos dentro de la malla urbana.

\section{Urbanización, localización y tipo de inmueble}

La zona en donde se insertan los inmuebles alquilados tiene un buen nivel de consolidación. El índice de urbanización ${ }^{10}$ para la zona titulada por la Cofopri es 54.6, muy parecido al caso control sin título de Cofopri (56.4). El hecho de que el caso control (Huáscar C) carezca de ese título no ha afectado su nivel de consolidación, ${ }^{11}$ que incluso es mayor en los pisos, aunque no en los techos de concreto (cuadro 3).

${ }^{8}$ Mientras que las compras y las ventas no son estadísticamente significativas en los asentamientos consolidados, en los que se hallan en proceso de consolidación no lo son los alquileres.

${ }^{9}$ En el 2006 apliqué una encuesta a las mismas zonas y el alquiler alcanzaba $62 \%$, lo cual muestra que el arrendamiento se ha incrementado notablemente.

${ }^{10} \mathrm{El}$ índice de urbanización se elaboró con diversos componentes (materiales de pisos, paredes y techos y servicios) a los cuales se otorgó una ponderación. La sumatoria de los porcentajes pesados arroja un promedio, a su vez multiplicado por los pesos definidos por el investigador, que da por resultado el índice. Véase el anexo.

${ }^{11}$ Esta paradoja contradice el discurso de la política de titulación que afirma que el título promueve la edificación de la casa. Sin embargo, existen las particularidades del caso, como que se trató de una reubicación pública, que en la década de 1980 la municipalidad otorgó títulos (aunque no registrados), y que entre 1968 y 2000 las autoridades instalaban servicios básicos en los asentamientos al margen de que estuvieran titulados o no (Calderón, 2005). 
CUADRO 3

Índice de urbanización en asentamientos consolidados

\begin{tabular}{|c|c|c|}
\hline Asentamientos consolidados & Titulados (\%) & Sin título (\%) \\
\hline \multicolumn{3}{|l|}{ Material del piso } \\
\hline Tierra & 1.4 & \\
\hline Cemento & 87.9 & 73.8 \\
\hline Cerámico/parquet & 10.6 & 26.2 \\
\hline \multicolumn{3}{|l|}{ Material de las paredes } \\
\hline Madera (Nordex) & 3.5 & 4.8 \\
\hline Ladrillo & 66.7 & 95.2 \\
\hline Concreto & 29.8 & \\
\hline \multicolumn{3}{|l|}{ Material del techo } \\
\hline Eternit & 2.1 & \\
\hline Calamina & 19.9 & 31.0 \\
\hline Concreto & 77.3 & 61.9 \\
\hline Madera & 0 & 4.8 \\
\hline Aluminio, metal & 0 & 2.4 \\
\hline \multicolumn{3}{|l|}{ Servicios $(\%)$} \\
\hline Con luz eléctrica & 100.0 & 97.6 \\
\hline Con agua & 99.3 & 100.0 \\
\hline Con desagüe & 97.9 & 100.0 \\
\hline Con teléfono fijo & 23.4 & 21.4 \\
\hline Calle pavimentada & 50.4 & 85.7 \\
\hline Índice de urbanización & 54.6 & 56.4 \\
\hline
\end{tabular}

FUENTE: Elaboración propia.

La localización se estableció procesando dos preguntas de la encuesta: "el motivo de primer orden que tuvo para alquilar el inmueble" y "a qué distancia queda el centro de trabajo del inquilino". El índice de localización del asentamiento titulado fue de 12.25, en tanto que el del no titulado fue de 21.15. Esto revela que los inquilinos de Huáscar C, que no cuentan con título de propiedad, perciben una mejor localización respecto a sus centros laborales que los del asentamiento titulado. ${ }^{12}$ Así, en los predios y viviendas no titulados se destacan los

${ }^{12}$ Por lo cual conviene distinguir el índice de localización basado en la percepción del ocupante respecto a su centro laboral, de la localización de los asentamientos con relación al centro histórico de la ciudad, criterio que se siguió inicialmente para la definición de los casos. 
CUADRO 4

Índice de localización en asentamientos consolidados

\begin{tabular}{lcc}
\hline & Titulado & Sin título \\
\cline { 2 - 3 } & $\%$ & $\%$ \\
\hline Motivo de primer orden para arrendar & & \\
Proximidad al trabajo & 26.2 & 47.6 \\
Trabajar en la vivienda & 5.7 & 2.4 \\
Acceso a escuela & 4.3 & 4.8 \\
Acceso a servicios y comercio & 7.8 & 4.8 \\
Proximidad a parientes & 8.5 & 28.6 \\
Costo del alquiler & 9.2 & 4.8 \\
Cambio en condición familiar & 26.2 & 0 \\
Distancia local de trabajo & & 26.2 \\
Mismo asentamiento & 12.3 & 33.3 \\
Menos de 30 minutos a pie & 10.6 & 7.1 \\
Más de 30 minutos a pie & 2.8 & 16.7 \\
Menos de 1 hora de transporte & 34.0 & 0 \\
Más de 1 hora de transporte & 3.5 & 21.15 \\
Indice de localización & 12.25 & \\
\hline
\end{tabular}

FUENTE: Elaboración propia.

indicadores de trabajo en el mismo asentamiento (26\%) y ubicación de menos de 30 minutos a pie. En cambio para los inquilinos que habitan en la zona titulada el centro de trabajo queda más lejos (indicador de menos de 1 hora de transporte).

En cuanto al tipo de inmuebles en alquiler, los cuartos o piezas solas predominan (62\%), seguidas lejanamente por los apartamentos $(16 \%)$, las viviendas con local comercial (13\%) y las casas en lote $(9 \%)$. La dinámica de densificación en la ciudad popular está generando la emergencia de un tipo de tugurio que deberían regular las autoridades. Hay indicadores que dan cuenta de la presencia de niveles de hacinamiento: $28 \%$ de los predios tiene un solo ocupante, seguido por $25 \%$ con tres, y $24 \%$ con cuatro ocupantes. Al menos en $25 \%$ de los cuartos o piezas alquiladas habitan tres y cuatro personas. 
CUADRO 5

Tipo de vivienda que se alquila en asentamientos consolidados

\begin{tabular}{lrrrrr}
\hline & \multicolumn{2}{c}{ Titulado } & & \multicolumn{2}{c}{ Sin título } \\
\cline { 2 - 3 } \cline { 5 - 6 } Tipo & Núm. & $\%$ & & Núm. & $\%$ \\
\hline Casa en lote & 13 & 9 & & 4 & 9 \\
Pieza o cuarto solo & 87 & 62 & & 28 & 67 \\
Lote sin construir & 0 & 0 & & 0 & 0 \\
Vivienda provisional & 0 & 0 & & 0 & 0 \\
Apartamento & 22 & 16 & & 10 & 24 \\
Vivienda y local comercial & 18 & 13 & & 0 & 0 \\
Vivienda compartida & 1 & 0 & & 0 & 0 \\
Total & 141 & 100 & & 42 & 100 \\
\hline
\end{tabular}

FUENTE: Elaboración propia.

\section{Los precios}

Tras haber reconocido las diferencias entre los asentamientos titulados y los no titulados en torno al índice de localización, más no con relación a la consolidación urbana, corresponde analizar los precios. Los inmuebles alquilados con título de propiedad Cofopri tienen un área promedio de $42.09 \mathrm{~m}^{2}$ y el pago promedio del alquiler es de 52.84 dólares de Estados Unidos por mes, lo cual constituye 1.25 dólares por $\mathrm{m}^{2}$. La mediana del alquiler es de 40 dólares por mes. Los predios no titulados tienen un área promedio sumamente reducida, de $15.9 \mathrm{~m}^{2}$, y el promedio que pagan de alquiler es de 37.1 dólares por mes, lo cual arroja un pago promedio de alquiler por metro cuadrado más alto, de 2.33 dólares por $\mathrm{m}^{2}$, esto es, casi el doble del alquiler de una propiedad más grande. La mediana es de 29 dólares por mes, lo que quiere decir que en general hay menos pagos en los no titulados, porque su área promedio es menor.

Se trata de un resultado que expresa ciertas paradojas. A pesar de que los inquilinos de la zona no titulada cuentan con menores ingresos familiares mensuales (257 dólares de Estados Unidos frente a 342), habitan en áreas más pequeñas y enfrentan condiciones más altas de hacinamiento, ${ }^{13}$ pagan más por el alquiler en términos de metro cua-

${ }^{13}$ En la zona consolidada no titulada hay mayor hacinamiento si se considera que tiene un promedio de 2.2 habitantes por inmueble frente a $15.9 \mathrm{~m}^{2}$, a diferencia de la zona titulada en que 2.7 pobladores deben habitar en un área promedio de 42 metros cuadrados. 


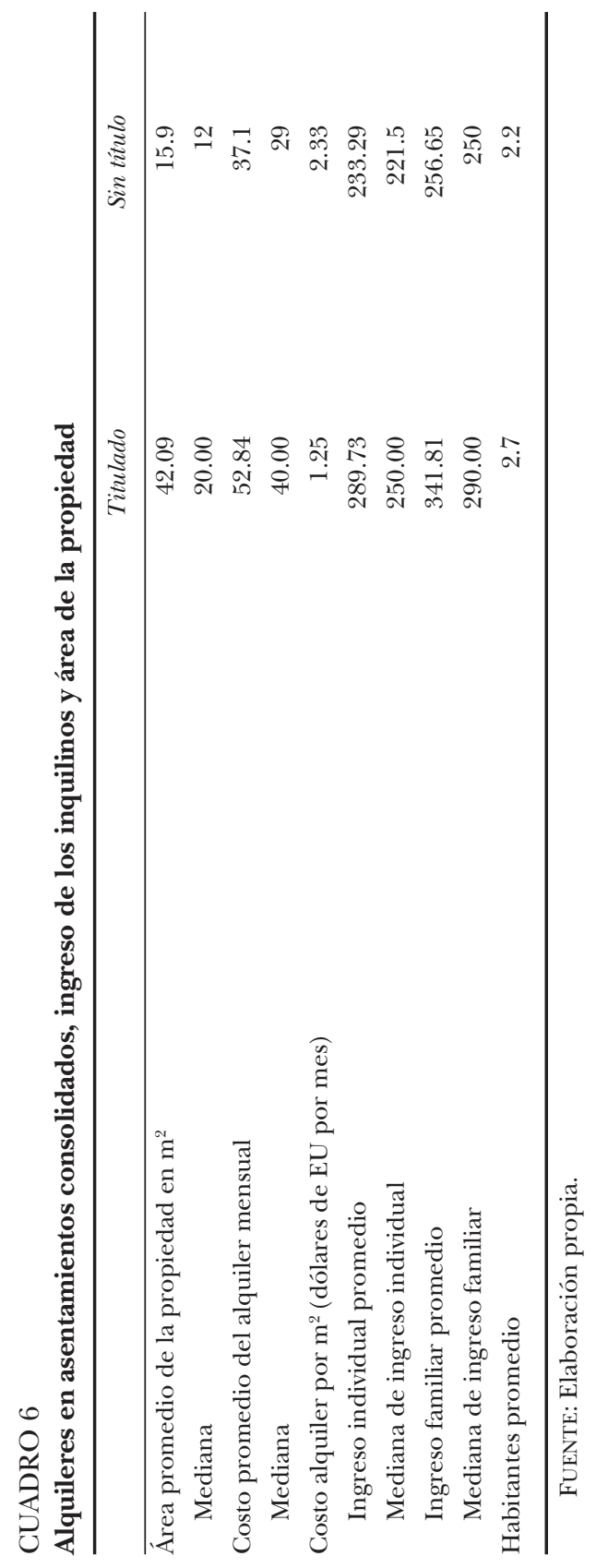


drado. En el cuadro 7 se observa que $67 \%$ de los inmuebles que se alquilan en la zona sin título se ubica en rangos de alquiler de 1 a 40 dólares y $31 \%$ en el rango de 41 a 80 dólares. Los inquilinos están dispuestos a pagar relativamente más por las ventajas de localización que perciben, y parecen indiferentes a que la zona cuente o no con título.

\section{Nivel de institucionalidad de transacciones}

Se elaboró un índice de institucionalidad con el objetivo de establecer el nivel de formalidad o no de las transacciones inmobiliarias; así se sometió directamente a prueba la proposición de la política de formalización relativa a que la titulación impulsa hacia mercados inmobiliarios formales. En realidad, tanto en la zona titulada como en la no titulada la mayoría de los contratos de alquiler son verbales y no se firman (53 y $55 \%$, respectivamente).

De acuerdo con el índice de institucionalidad, hay mayor formalidad en las transacciones entre los agentes en la zona no titulada que en la titulada. El índice de institucionalidad se ha construido sobre indicadores de cómo se obtuvo la información para alquilar el inmueble, el tipo de contrato, la duración del contrato, la cercanía o no entre los arrendadores y los inquilinos, la existencia de reajuste y la responsabilidad en los pagos por servicios de agua y electricidad. ${ }^{14}$

El índice de institucionalidad arroja un resultado paradójico: es mayor en la zona que carece de título Cofopri (41.8) que en la zona titulada (33.37). Los indicadores que determinan la diferencia son: la duración de los contratos -más prolongados en el asentamiento no titulado- y el pago por los servicios a cargo de los inquilinos en los asentamientos no titulados, a semejanza de este tipo de transacciones en la ciudad formal.

En cuanto a otros indicadores:

- En los asentamientos titulados por la Cofopri $58 \%$ de los arrendadores habita en el mismo inmueble que el inquilino; esto se incrementa a $67 \%$ en los asentamientos no titulados. En ambos

${ }^{14}$ La idea de generar un índice de este tipo fue desarrollada por Parias (2006). En este caso las ponderaciones elevan el peso de las situaciones formales. Por ejemplo, un contrato escrito tiene más peso que un contrato verbal, la información por redes sociales (parientes, amigos, boca a boca) es menos ponderada que la que se ofrece por asociaciones de vecinos o anuncios, la duración del contrato se estima como un indicador de confianza entre los agentes. 


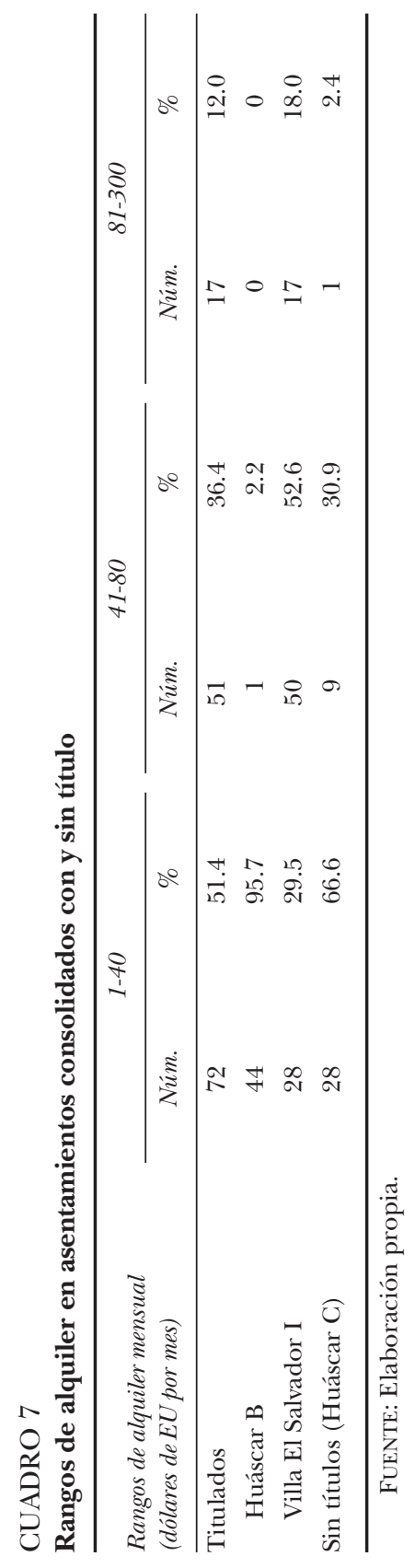


es común que los propietarios o poseedores habiliten cuartos ampliando su inmueble y que permanezcan en una parte de él. A su vez, en la zona titulada hay mayor presencia de los propietarios en los asentamientos (21\%), y en $79 \%$ hay relaciones "cara a cara" entre arrendadores e inquilinos. En la zona no titulada $7 \%$ es habitante del mismo distrito y $21 \%$ de otro distrito, lo cual muestra que los propietarios que alquilan y que no viven en el asentamiento constituyen un mayor porcentaje que en el caso del asentamiento titulado. Este argumento contradice a quienes piensan que la no existencia de un título de propiedad puede generar en los dueños el temor a que el inquilino se adueñe de la propiedad.

- Casi la mitad de los inquilinos (46\%) en el asentamiento con título Cofopri desconocía si el propietario tenía o no título de propiedad, asunto que parecería no preocuparles demasiado. En el asentamiento no titulado $48 \%$ de los inquilinos también desconocía esta información.

En conclusión, el que un predio cuente con título de propiedad no garantiza que se alquile conforme a la formalidad y la institucionalidad. Aunque estén dentro de la formalidad jurídica, los predios inscritos en el mercado de alquiler no realizan transacciones dentro de la legalidad. Antes bien, hay un mayor índice de institucionalidad -y probablemente de confianza- en la zona no titulada. La tenencia de un título Cofopri no inclina institucionalmente a los agentes a efectuar transacciones dentro de la formalidad.

\section{Asentamientos no consolidados}

Los asentamientos no consolidados, con unos 8 a 12 años de existencia, se formalizaron hacia el año 2000 en la gran ola de titulación que se organizó por entonces. Sus ocupantes han tenido entre sus manos el título de propiedad desde hace al menos ocho años; lo recibieron cuando aún la zona se encontraba en las etapas iniciales de urbanización. El mercado inmobiliario que predomina es el de compraventa. Las compras predominan con $65 \%$ de las transacciones, $25 \%$ vende y sólo $10 \%$ está en alquiler. ${ }^{15}$

\footnotetext{
${ }^{15}$ Esta tendencia es similar en el caso control, no titulado, en el cual las compras de inmuebles llegan a $69 \%$ y las ventas a 17 por ciento.
} 
CUADRO 8

Índice de institucionalidad en asentamientos consolidados

\begin{tabular}{|c|c|c|}
\hline Componente & Titulado (\%) & Sin título (\%) \\
\hline \multicolumn{3}{|l|}{ Información } \\
\hline Boca a boca & 6.4 & 4.8 \\
\hline Por parientes & 27.7 & 45.2 \\
\hline Por amigos & 19.9 & 19.0 \\
\hline Asociación de vecinos & 0 & 0 \\
\hline Anuncio en espacio público & 41.1 & 0 \\
\hline Anuncio en local comercial & 3.5 & 2.4 \\
\hline Cartel en inmueble & 7.0 & 28.6 \\
\hline \multicolumn{3}{|l|}{ Contrato } \\
\hline Verbal & 52.5 & 54.8 \\
\hline Firmado & 47.5 & 45.2 \\
\hline \multicolumn{3}{|l|}{ Duración del contrato } \\
\hline Seis meses & 37.0 & 4.8 \\
\hline Doce meses & 48.2 & 92.9 \\
\hline Más de doce meses & 8.4 & 0 \\
\hline \multicolumn{3}{|l|}{ Previsión de reajuste } \\
\hline No tiene & 89.4 & 97.6 \\
\hline Sí tiene & 7.8 & 2.4 \\
\hline \multicolumn{3}{|l|}{ Arrendador vive } \\
\hline Misma vivienda & 0.7 & 0 \\
\hline Mismo inmueble & 56.7 & 66.7 \\
\hline Mismo asentamiento & 21.3 & 4.8 \\
\hline Mismo distrito & 10.6 & 7.1 \\
\hline Otro distrito & 6.4 & 21.4 \\
\hline Otra ciudad & 2.8 & 0 \\
\hline \multicolumn{3}{|l|}{ Pago agua y electricidad } \\
\hline Arrendador & 13.5 & 7.1 \\
\hline Mixto & 15.6 & 0 \\
\hline Inquilino & 70.2 & 92.9 \\
\hline Índice de institucionalidad & 33.37 & 41.8 \\
\hline
\end{tabular}

FUENTE: Elaboración propia. 
Entre los asentamientos no consolidados que aún no cuentan con título de propiedad también opera un activo mercado inmobiliario, pero con otras connotaciones institucionales y económicas, en tanto enfrenta una demanda compuesta por sectores de menores recursos.

Una pregunta recurrente en torno al mercado inmobiliario en las zonas urbanas de pobres y de sectores de bajos ingresos es ¿por qué venden?, dado que se trata de personas y familias pobres más bien necesitadas de una vivienda. Asimismo, ¿por qué hay allí un mercado inmobiliario? En realidad la mayoría de los ocupantes de estos asentamientos requiere las viviendas para residir en ellas (valor de uso). Asimismo, el stock de viviendas y terrenos vendidos se mantiene en los límites convencionales: en Ampliaciones Huáscar, de los que están vendiendo ${ }^{16} 79 \%$ fue invasor original de la tierra y $21 \%$ ya había adquirido el inmueble, lo cual revela que en un lapso promedio de diez años sólo $20 \%$ de los predios había cambiado de propietario.

El mercado inmobiliario existe en las zonas no consolidadas porque lo demanda una población que requiere un terreno o vivienda, que cuenta con algún dinero, y que no está dispuesta a invadir un terreno y a asumir el "costo de invasión". Esta demanda estimula una oferta que debe adecuarse a ella. Esta investigación revela que hay un mercado de terrenos titulados y no titulados, establecidos en correspondencia con dos estratos diferentes. Un terreno sin título es menos caro y hacia él se orientará la demanda de menores recursos.

En las zonas tituladas la oferta obedece a factores de rentabilidad o a la necesidad impostergable de vender el terreno por razones de salud o matrimonio. Parte de esa oferta está constituida por personas que tienen dos terrenos, algo que se genera por los bajos controles de las autoridades encargadas de la formalización. Así, los poseedores de dos lotes pueden residir en uno y vender el otro. ${ }^{17}$ Éste es un tópico recurrente entre el sector académico y el de la cooperación, pero no preocupa mucho a las autoridades.

De los vendedores de las zonas tituladas a quienes se interrogó sobre el uso futuro del dinero que obtendrán por la venta del predio, $39 \%$ declaró que lo destinará a adquirir otro inmueble, $25 \%$ lo inver-

${ }^{16}$ En Ampliaciones Huáscar los vendedores son 28 en términos absolutos, de ahí que no sea posible hacer inferencias estadísticas y estas proposiciones deban considerarse referenciales.

${ }^{17}$ Esto explica que en los asentamientos no consolidados entre 20 y $30 \%$ de los lotes estén vacantes, titulados pero no ocupados, como muestran diversos estudios (Calderón, 2007, 2007a; Ramírez y Riofrío, 2006) y diagnósticos de las firmas de ingenieros que efectúan obras de agua y saneamiento. 
tirá como capital en un negocio y 14\% lo utilizará en un viaje en busca de una oportunidad laboral. Esto es, más de la mitad de los que vendieron ya contaban con un terreno y una vivienda. ${ }^{18}$

\section{Nivel de urbanización, localización y tipo de predio}

En los asentamientos titulados no consolidados con diez años de existencia, ha habido avances con la provisión de servicios básicos como luz eléctrica y agua potable. En cambio la unidad de vivienda continúa siendo sumamente precaria. El índice de urbanización elaborado respecto a los inmuebles transados muestra en los titulados 32.33. Con todo, este índice es mucho mayor que el de los asentamientos no titulados, en donde alcanza 18.88. Esta diferencia, como lo muestra el cuadro 9 , se establece a partir de los indicadores de materiales de pisos y techos y de servicios básicos. Esta situación concuerda con el hecho de que en los asentamientos no titulados el lote sin construir alcanza $71 \%$ de las compras.

El nexo entre la titulación y los mayores avances en construcción y servicios básicos parece dar la razón a quienes sostienen que la titulación acarrea un aumento de los niveles de inversión para mejorar la calidad de la vivienda (Apoyo Consultoría, 2000; Kagawa, 2000). Si esto se reconoce y a la vez se excluye una explicación de la inversión por el acceso al crédito, ha de atribuirse este logro al incremento de la seguridad (Field, 2005).

Como se ha indicado (Calderón, 2003), la correlación entre la titulación y un mayor nivel de urbanización debe considerar adecuadamente las modificaciones que se han venido dando en la política urbana, que van más allá de la seguridad de tenencia. Hasta el año 2000 el Estado peruano no exigía la condición de tenencia del título de propiedad para instalar los servicios de agua y saneamiento, ni para otorgar el crédito subsidiado del Banco de Materiales para edificar las viviendas. A partir del 2001 el Estado en cierto modo ha "ordenado" la secuencia del desarrollo urbano en los asentamientos barriales al exigir la tenencia del título como un requisito para el acceso a los servicios básicos y los préstamos públicos para mejora de la vivienda. Esta decisión resulta coherente con el estímulo a la política de formalización de la propiedad. su casa.

${ }^{18}$ Fue curioso que un encuestado declarara que vendía el inmueble para mejorar 
CUADRO 9

Índice de urbanización en asentamientos no consolidados

\begin{tabular}{|c|c|c|}
\hline Componentes & Titulado (\%) & Sin título (\%) \\
\hline Lote sin construir & 28.8 & 70.7 \\
\hline \multicolumn{3}{|l|}{ Material piso } \\
\hline Tierra & 42.5 & 17.2 \\
\hline Madera & 1.4 & 1.7 \\
\hline Cemento & 26.0 & 10.3 \\
\hline \multicolumn{3}{|l|}{ Material paredes } \\
\hline Quincha & 1.4 & 1.7 \\
\hline Madera (Nordex) & 52.1 & 24.1 \\
\hline Cartón, plástico & & 3.4 \\
\hline Ladrillo & 6.8 & 0 \\
\hline Concreto & 9.6 & 0 \\
\hline Lote sin construir & 28.8 & 70.7 \\
\hline \multicolumn{3}{|l|}{ Material del techo } \\
\hline Eternit & 9.6 & 3.4 \\
\hline Calamina & 54.8 & 13.8 \\
\hline Concreto & 6.8 & 1.7 \\
\hline Plástico, cartón, estera & & 10.3 \\
\hline Lote sin construir & 28.8 & 70.7 \\
\hline \multicolumn{3}{|l|}{ Servicios (\%) } \\
\hline Con luz eléctrica & 90.4 & 77.6 \\
\hline Con agua & 75.3 & 60.3 \\
\hline Con desagüe & 80.8 & 36.2 \\
\hline Con teléfono fijo & 1.4 & 3.4 \\
\hline Calle pavimentada & 6.8 & 1.7 \\
\hline Índice de urbanización & 32.33 & 18.88 \\
\hline
\end{tabular}

FUENTE: Elaboración propia.

En cuanto a la localización de los asentamientos no consolidados, titulados o no, el índice de localización no muestra mayores diferencias: 12.68 frente a 11.75. En ambos casos la mitad de los compradores gasta más de una hora en transporte para llegar a su trabajo, por lo que podría decirse que la diferencia de precio la hacen el nivel de urbanización y el título de propiedad.

De los inmuebles que se han comprado en asentamientos titulados, $37 \%$ son casas en lote, $33 \%$ viviendas provisionales y $29 \%$ lotes sin cons- 
CUADRO 10

Índice de localización en asentamientos no consolidados

\begin{tabular}{lcc}
\hline Componente & Titulado (\%) & Sin título (\%) \\
\hline Principal motivo para comprar & 12.3 & 12.1 \\
$\quad$ Proximidad al trabajo & 21.9 & 0 \\
Acceso a la escuela & 1.4 & 0 \\
Acceso a los servicios y el comercio & 6.9 & 3.4 \\
Proximidad a parientes o amigos & 17.8 & 10.3 \\
Cambio en la condición familiar & 26.0 & 56.9 \\
Ya vivió en la localidad & 1.4 & 12.1 \\
Estatus social & & \\
Distancia del trabajo & 4.1 & 5.2 \\
Mismo asentamiento & 5.5 & 13.8 \\
Menos de 30 minutos a pie & & 5.2 \\
Más de 30 minutos a pie & 35.6 & 27.6 \\
Menos de 1 hora de transporte & 49.3 & 48.3 \\
Más de 1 hora de transporte & 12.68 & 11.75 \\
Indice de localización &
\end{tabular}

FUENTE: Elaboración propia.

CUADRO 11

Inmuebles adquiridos en asentamientos no consolidados

\begin{tabular}{lrrrrr}
\hline & \multicolumn{2}{c}{ Titulado } & & \multicolumn{2}{c}{ Sin título } \\
\cline { 2 - 3 } \cline { 5 - 6 } Tipo de inmueble & Núm. & $\%$ & & Núm. & $\%$ \\
\hline Casa en lote & 27 & 37 & & 9 & 15.5 \\
Pieza o cuarto solo & 1 & 1 & & 1 & 1.7 \\
Lote sin construir & 21 & 29 & & 41 & 70.7 \\
Vivienda provisional & 24 & 33 & & 7 & 12.1 \\
\hline
\end{tabular}

FUENTE: Elaboración propia.

truir. El área promedio es de $102.59 \mathrm{~m}^{2}$ y la mediana es $90 \mathrm{~m}^{2}$. Obsérvese en el caso control no titulado el alto porcentaje de ventas de lotes no construidos $(71 \%)$, modalidad ampliamente mayoritaria. ${ }^{19}$

${ }^{19}$ Cabe mencionar que en los inmuebles en oferta en la zona titulada en consolidación el área promedio es de $99.29 \mathrm{~m}^{2}$ y la mediana es de $90 \mathrm{~m}^{2}$. El precio por un lote promedio es de 3265 dólares de Estados Unidos (a 32.8 dólares por $\mathrm{m}^{2}$ ), aunque la mediana es 2590 dólares. Se ofrecen viviendas provisionales (53\%), casas en lote (36\%) 


\section{Los precios}

En los asentamientos titulados no consolidados se pagan en promedio 1637.51 dólares de Estados Unidos (4 700 nuevos soles) por un lote de $102 \mathrm{~m}^{2}$, esto es 15.96 dólares por $\mathrm{m}^{2}$. Este precio es muy superior al de los terrenos ubicados en los asentamientos no titulados, cuyo costo promedio es de 629.71 dólares, a razón de $90 \mathrm{~m}^{2}$, lo que arroja un precio de 5.5 dólares por $\mathrm{m}^{2}$, tres veces menor. Esta amplia diferencia se corrobora al observar que en los asentamientos no titulados se concentran los predios de menor precio (cuadro 12).

El precio más alto de los predios titulados no sólo resulta de un mayor índice de urbanización, también del aporte del título de propiedad como tal. La muestra de compras de Ampliaciones Huáscar, considerando las variables significativas, y sobre un $\mathrm{R}^{2}$ de 0.621 , arroja que la beta de contribución del título al precio de compra es de 0.457 , seguido de materiales de piso (0.303) y el número de cuartos $(0.234) .^{20}$

Las percepciones de los compradores de lotes titulados que declararon cuánto hubieran pagado por el mismo lote si no hubiera contado con el título, arrojaron un monto promedio de 654.75 dólares de Estados Unidos, muy inferior al que pagaron con título, que fue de 1745.50 dólares. El diferencial que deriva del título es de 1087 dólares según la percepción del comprador. ${ }^{21}$ Los compradores valoran un terreno titulado 2.6 veces más. ${ }^{22}$

y lotes sin construir (11\%). Predomina la oferta de inmuebles con pisos de tierra (54\%) y de cemento $(36 \%)$, paredes de madera $(75 \%)$ y techos de calamina $(61 \%)$. Tiene agua, desagüe y luz eléctrica $71 \%$ y predomina la venta de dos cuartos (43 por ciento).

${ }^{20} \mathrm{R}^{2}$ es el coeficiente de determinación, que es el cuadrado del coeficiente de correlación de Spearman, prueba no paramétrica que mide la asociación o interdependencia entre dos variables continuas. Su valor va de cero a uno. Es uno de los indicadores básicos en el análisis de regresión.

${ }^{21}$ Este hallazgo corrobora el estudio cualitativo de Cuánto Instituto (2001) que determinó que los propietarios reconocían el valor del título de propiedad como instrumento de plenos derechos y pensaban que incrementaba el valor del precio entre 20 y $30 \%$. En nuestro caso el aporte del título al valor es mucho mayor. También corrobora la encuesta de Apoyo Consultoría (2003) que, aplicada no sobre precios de transacciones reales sino sobre un modelo matemático mediante un enfoque de precios hedónicos, mostró que el diferencial de precios causado por el título de propiedad era de aproximadamente 925 dólares de Estados Unidos, lo que equivalía a 25\% del valor promedio de un lote sin titular.

${ }^{22}$ Los propulsores de la formalización suelen multiplicar esa cifra por el número de "primeros títulos" otorgados por la Cofopri (565 536), derivando un beneficio económico bruto de 523 millones de dólares. Un proceso similar podría hacerse con mis cifras, aunque conviene hacer las estimaciones sobre un aproximado al número de transacciones probables y no sobre el total de títulos otorgados. 
CUADRO 12

Precios de compra en asentamientos no consolidados

\begin{tabular}{lccccc}
\hline & \multicolumn{2}{c}{ Titulado } & & \multicolumn{2}{c}{ Sin título } \\
\cline { 2 - 3 } \cline { 5 - 6 } Rangos de precios (dólares de EU) & Núm. & $\%$ & & Núm. & $\%$ \\
\hline $1-1100$ & 13 & 17.8 & & 46 & 79.3 \\
$1101-1900$ & 28 & 38.4 & & 11 & 32.7 \\
$1901-3000$ & 9 & 12.0 & & 0 & 0 \\
$3000-10000$ & 21 & 28.8 & & 1 & 1.7 \\
Total & 73 & & & 58 & \\
\hline
\end{tabular}

FUENTE: Elaboración propia.

Nivel de institucionalidad de las transacciones

Los impulsores de la formalización de la propiedad sostienen que los títulos reducirán los costos de las transacciones e incrementarán un mercado inmobiliario que tenderá a insertarse en la formalidad. El estudio muestra que aunque se observan avances en esa dirección, aún parece distante la promoción de mercados inmobiliarios formales.

Las transacciones en los asentamientos titulados tienen un índice de institucionalidad de 38 , mayor que en los no titulados (30.2\%). Dos indicadores inciden en estos resultados. En primer lugar, en las viviendas tituladas predominan los contratos de compraventa escritos, a diferencia de lo que ocurre en los asentamientos no titulados, en donde tienden a ser verbales, de palabra. En segundo lugar, sólo 25\% de las transacciones se registra ante la Superintendencia Nacional de Registros Públicos (Sunarp), algo que, como es obvio, no puede ocurrir en asentamientos no titulados. No obstante se debe reconocer que es insuficiente el registro de sólo $25 \%$ de las transacciones.

Los contratos escritos otorgan mayor seguridad a los agentes que participan de las transacciones. De los compradores encuestados $60 \%$ declaró que no habría comprado un predio sin título de propiedad. Asimismo el título de propiedad está adquiriendo una mayor valorización social por razones de seguridad y de prestigio.

No obstante, hay indicios de que la formalidad del mercado inmobiliario aún está lejana. De los compradores de lotes titulados por la Cofopri 18\% no hizo ningún tipo de registro de la adquisición, mientras que $56 \%$ sólo lo hizo ante notario público. Como se ha indicado, si los actos posteriores ("segundos actos") que realizan los titulados de Cofo- 
pri, tales como las transferencias de titularidad del predio formalizado, no se inscriben en el registro, éste se volverá obsoleto y constituirá un retroceso frente a lo que alcanzó la política (Webb et al., 2006: 58).

En cuanto al pago de impuestos, sólo $16 \%$ de los compradores había cumplido con el de transacción (llamado de alcabala), y sólo $4 \%$ había pagado el impuesto predial correspondiente a la municipalidad.

No se puede suponer que luego de registrar las propiedades los actores se ceñirán a las normas institucionales de manera mecánica. Esto revive el viejo debate respecto a si los costos de actuar en la formalidad siguen siendo altos y por eso los agentes actúan fuera de ella.

Las transacciones en los asentamientos no titulados constituyen un mundo por explorar. Las entrevistas cualitativas se interesaron por

CUADRO 13

Índice de institucionalidad en asentamientos no consolidados

\begin{tabular}{lcc}
\hline Componente & Titulado (\%) & Sin título (\%) \\
\hline Información & 95.9 & 22.4 \\
Boca a boca & 2.7 & 46.6 \\
Por parientes & 1.4 & 25.9 \\
Por amigos & 0 & 3.4 \\
Asociación de vecinos & & \\
Registro de la transacción & 17.8 & 13.8 \\
No registró & 0 & 5.2 \\
Otros & 1.4 & 72.4 \\
Directivas asociación de vecinos & 56.2 & 8.6 \\
Notario público & 24.7 & 0 \\
Sunarp & & 27.6 \\
Contrato de compraventa & 95.9 & 72.4 \\
Escrito & 4.1 & 0 \\
Verbal & & 100.0 \\
Pago de impuesto de transacción & 16.4 & 5.2 \\
Sí & 80.8 & 94.8 \\
No & & 30.2 \\
Pago de predial en los últimos años & 4.1 & \\
Sí & 95.9 & 38.0 \\
No & & \\
Indice de institucionalidad & & \\
\hline
\end{tabular}

FUENTE: Elaboración propia. 
el hecho que se adquieran inmuebles sin título de propiedad. Al respecto los compradores emitieron un juicio despojado de valores morales frente a la ley. Recordaron con dolor las carencias que sufrían cuando habitaban en cuartos de alquiler, que deben ser como los que se mencionaron en los asentamientos consolidados, y su necesidad imperiosa de adquirir un terreno. En esas condiciones se les ofrecen las opciones de adquirir predios titulados o no, y es el menor precio de los segundos lo que inclina su decisión. Para ellos se trata de mejorar sus condiciones de vida, tener seguridad y tranquilidad, y como los predios titulados son más caros deben recurrir al mercado ilegal para alcanzar sus objetivos.

La encuesta muestra que sólo $28 \%$ establece contratos escritos de compra y venta. El mercado inmobiliario es informal y se desarrolla en un ambiente precario. A los poseedores de facto de la tierra que cuentan con cierto reconocimiento público (municipal) o de la organización vecinal se les considera socialmente como "dueños". El tráfico de lotes es altamente informal. Hay mecanismos de administración de la tierra a cargo de directivas vecinales que permiten acceder a los lotes a precios de 70 a 120 dólares de Estados Unidos.

\section{Discusión}

El estudio brinda la posibilidad de responder a las preguntas clave que se formularon inicialmente. El título de propiedad aporta un peso importante al valor del inmueble en los procesos de compra y venta; representa un premio de más de mil dólares si se le compara con un lote sin título en las zonas no consolidadas. No obstante, el mercado inmobiliario en asentamientos titulados no necesariamente se dirige hacia la formalidad. Hay un peso fuerte de informalidad en los alquileres y las compraventas.

Si bien se alcanzó el beneficio económico esperado por las propuestas de formalización (aporte del título al precio), no se está cumpliendo con desarrollar una práctica institucional que formalice los mercados.

Conviene explicar esta antinomia siguiendo nuestro enfoque, porque la persistencia de la informalidad en los mercados inmobiliarios en las zonas tituladas responde a las prácticas razonables que los actores llevan a efecto en busca de la mejora de sus condiciones de vida. Una familia con ingresos suficientes para huir del cuarto de alquiler 


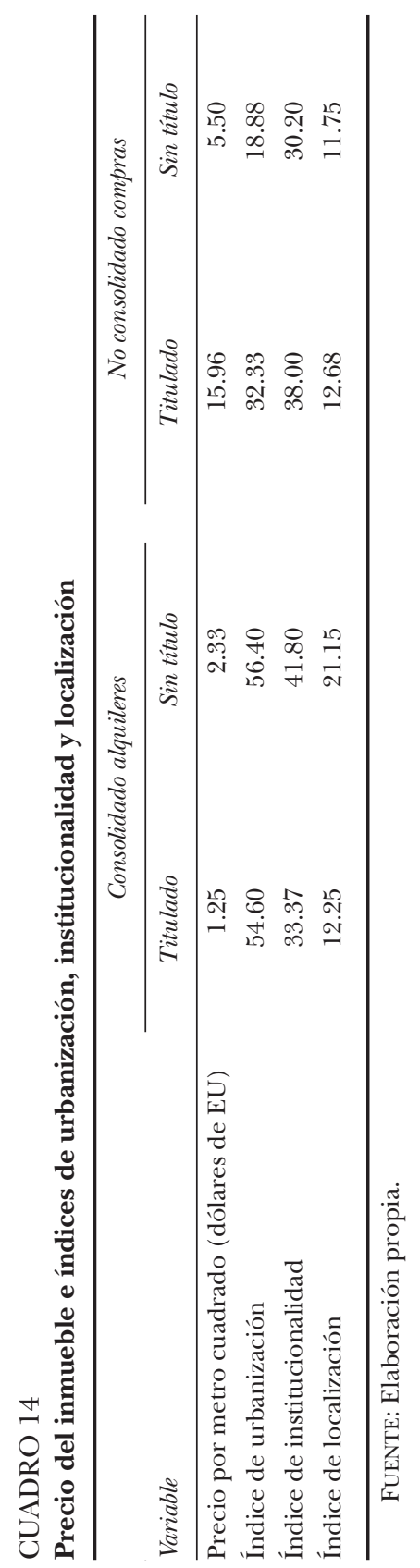


comprará un terreno aunque no tenga título de propiedad. El arrendador de la barriada consolidada de ese mismo cuarto optará por no declarar esos ingresos a las autoridades tributarias, pues al hacerlo reduciría su rentabilidad. El comprador de un lote en un asentamiento no consolidado que registra la transacción verá que se incrementan sus costos por el pago de impuestos y procedimientos. En todos los casos el pagar los costos de la formalidad resulta más oneroso que actuar en la informalidad.

Los títulos de propiedad, que se asumen mayormente como correlato de la resolución de la necesidad de vivienda, son valorizados tanto por quienes compran predios titulados como por los que compran sin título. La valorización del título se asocia a ser "dueño" reconocido por el Estado, a tener acceso a préstamos, seguridad y mejora de la vivienda. El título posee un valor económico. Así, quienes carecen de él reconocen las gestiones y gastos que deberán hacer para obtenerlo, lo cual explica que cueste más. También se confiere una consideración social, simbólica y jurídica al predio titulado, que se traslada al precio. El cuadro 15 muestra los beneficios que se perciben en los títulos de propiedad.

La política de la formalización de la propiedad ha generado expectativas en los actores, una subida de precios y una mayor valorización de la posibilidad de venta. Los compradores de predios titulados son plenamente conscientes de la posibilidad de la venta del predio (43\%), factor más valorizado que la propia seguridad jurídica (19\%) o el acceso al crédito formal (19\%). Estas transacciones no están produciendo procesos de "invasión-sucesión" en términos de estratos sociales, si se estima que el ingreso familiar promedio mensual de los compradores (378 dólares de Estados Unidos) es igual al de los vendedores. No hay desplazamientos de pobres por menos pobres, o viceversa.

El alza del precio del terreno por la valorización del título es una buena noticia para el que vende. Para la demanda de menos recursos, aquella que puede evitar el costo de invadir pero no puede comprar un terreno titulado, una mayor titulación ocasionará una elevación de precios y restringirá las perspectivas de adquirir un inmueble. Esto es, se acortan los canales mercantiles de acceso al suelo para los sectores de menores ingresos.

Respecto a la idea de que una titulación total a la larga reducirá el precio de los inmuebles, estamos muy lejos de ello. Esto supondría un reforzamiento de la política de titulación, y, a la vez, una política de vivienda o de acceso ordenado al suelo que neutralice o torne in- 


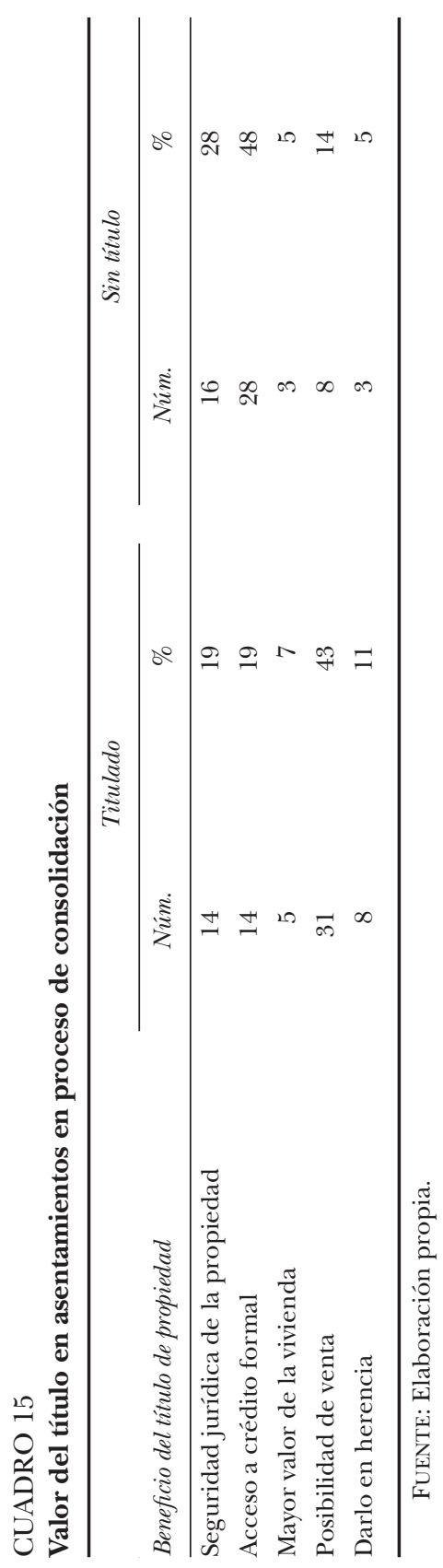


necesarias las invasiones y la formación de barriadas. Un escenario en el que se ha regularizado lo informal y a la vez se ha frenado el crecimiento de la ciudad informal requiere mucho más que una política de distribución de títulos de propiedad.

Con una perspectiva histórica se observa que las barriadas viejas y consolidadas que absorbieron la llegada a las ciudades de los inmigrantes entre las décadas de 1960-1980 acogen hoy modalidades de alquiler de verdaderos tugurios, al servicio de quienes siguen llegando a la ciudad y no desean invadir un terreno, que no son extremadamente pobres y que sólo pueden costearse un terreno sin título en las barriadas que otros invadieron. Su inserción en el mercado inmobiliario los lleva a habitar en asentamientos sin servicios, sin título y con alta vulnerabilidad social. Esto es, acceden a la ciudad por vías mercantiles ilegales. Un modo de evitar que esta rueda siga girando sería que las políticas de vivienda consideraran y atendieran esta demanda de bajos ingresos.

\section{ANEXO}

\section{Elaboración de los índices}

En la investigación se ha recurrido a elaborar índices de urbanización, localización e institucionalización con el objetivo de afinar el análisis para explicar el precio del suelo y la formalidad de las transacciones. El índice, entendido como una propuesta en construcción, es un cuantificador con el que se trata de valorar la situación del fenómeno en estudio, y es concurrente en la medida en que es capaz de expresar varias características de una distribución en una sola, la cual sirve para comparar situaciones entre asentamientos titulados o no y entre tiempos diferentes.

1) El índice de urbanización da cuenta del nivel de consolidación urbanística de los asentamientos considerando dos variables: la vivienda (y sus indicadores de materiales de pisos, paredes y techos) y los servicios (y sus indicadores de agua, luz, desagüe, teléfono y calle pavimentada). Entre más elevado es el valor del índice, más alto el nivel de urbanización. Un mayor nivel de consolidación en cada indicador, por ejemplo piso de madera a diferencia de piso de tierra, tiene un peso mayor, y por éste se multiplica la distribución porcentual obtenida. 
2) Con el índice de localización se busca expresar la "geografía de oportunidades" que se ofrecen a las familias compradoras o inquilinas de inmuebles. Se establece con base en dos variables: el motivo de compra o alquiler y la distancia al centro de trabajo.

La variable de motivo de compra o alquiler remite a la intención de la familia, y sus indicadores se refieren a factores económicos (proximidad al trabajo, trabajar en la vivienda) con un peso 3, a factores geográficos y sociales (acceso a escuela o comercio, redes sociales) con un peso 2, y a factores sociales (vivencia anterior, estatus social, cambio en la condición familiar) y económicos (bajo costo del alquiler) con un peso 1. Los aspectos económicos, salvo el costo de alquiler, tienen un mayor peso conforme al supuesto de que las familias obtienen un mayor beneficio diferencial con la proximidad al trabajo.

La variable distancia al centro de trabajo es estrictamente económica, y se asemeja a las consideraciones de la economía espacial (urbana). A menor tiempo de desplazamiento mayor peso y mayor aporte al índice.

3) Mediante el índice de institucionalización se busca establecer el nivel de formalidad de las transacciones inmobiliarias. A mayor puntaje del índice, mayor formalidad. Considera la variable obtención de información, da un peso 2 a ciertos indicadores como su provisión por la asociación de vecinos, lo cual implica mayor institucionalización, a diferencia de su provisión por redes sociales (parientes, boca a boca y amigos) con un peso 1. En la variable de registro de la transacción el indicador de registro ante la autoridad pertinente tiene un peso 3, ante notario público 2, y ante directivas de asentamiento u otros 1. En la variable de contrato de compraventa el indicador de contrato escrito tiene un peso de 3 frente a 1 del contrato sólo verbal. En la variable de pago de impuestos (predial y de transacción) el haberlo realizado tiene un peso 2, frente a cero que representa no haberlo hecho.

El análisis compara el precio del suelo en los asentamientos titulados y los no titulados; se vale de los índices de urbanización, localización e institucionalidad con el doble propósito de explicar las diferencias entre los precios y el despliegue de las prácticas institucionales. 


\section{Bibliografía}

Aldana, Úrsula y Ricardo Fort (2001), Efectos de la titulación y registro de tierras sobre el grado de capitalización en la agricultura peruana, Lima, INEI/GRADE.

Alvarado, Javier (1995), "Los derechos de propiedad de la tierra: una aproximación desde la economía”, Debate Agrario, núm. 23, Lima.

Apoyo Consultoría (2000), Encuesta de Linea de Base. Reporte final, Lima, Proyecto Derechos de Propiedad Urbana/Cofopri.

Apoyo Consultoría (2003), Estudio para el diseño de un sistema de información de precios del mercado inmobiliario urbano marginal e implementación del mismo, Lima, Proyecto Derechos de Propiedad Urbana/Cofopri.

Baharoglu, Deniz (2002), "World Bank Experience in Land Management and the Debate on Tenure Security", Washington, World Bank (Urban and Local Government Background Series, 16).

Barrantes, Roxana y Carolina Trivelli (1994), "Tenencia de tierras y liberalización de mercados: un estudio de caso del Valle de Cañete", en Carlos I. Degregori, Javier Escobal y Javier Iguíniz (coords.), Perú, el problema agrario en debate, Lima, Sepia.

Bourdieu, Pierre (2005), Una invitación a la sociología reflexiva, México, Siglo XXI.

Briceño León, Roberto (2006), "Cinco dimensiones sociales del mercado de tierra informal en Caracas", taller Mercados de Suelo en Asentamientos Informales en América Latina, Panamá, 18 a 20 de septiembre.

Calderón, Julio (2001), "Análisis comparativo de la población beneficiada y la no beneficiada por el Plan Nacional de Formalización", en ¿ Ha mejorado el bienestar de la población?, Lima, INEI.

Calderón, Julio (2002), "The Mystery of Credit", Land Lines. Newsletter of the Lincoln Institute of Land Policy, vol. 14, núm. 2, pp. 5-8.

Calderón, Julio (2003), Propiedad y crédito. La formalización de la propiedad en el Perú, Quito, PGU-Hábitat.

Calderón, Julio (2005), La ciudad ilegal. Lima en el siglo XX, Lima, UNMSM.

Calderón, Julio (2006), Mercado de tierras urbanas, propiedad y pobreza, Lima, LILP-SINCOS.

Calderón, Julio (2007), Mercados inmobiliarios en asentamientos informales de Lima y procesos de diferenciación social, Cambridge, Lincoln Institute/Infomercados.

Calderón, Julio (2007a), "Después de la formalización ¿Qué sigue?”, World Bank Urban Research Symposium, Washington, 14 a 16 de mayo.

Caria, Antonio (2008), Títulos sin desarrollo: los efectos de la titulación de tierras en los nuevos barrios de Lima, Lima, Desco.

Clichevsky, Nora (2003), Pobreza y acceso al suelo urbano. Algunas interrogantes sobre las políticas de regularización en América Latina, Santiago, CEPAL.

Cuánto Instituto (2001), "Estudio cualitativo del mercado inmobiliario urbano marginal. Informe final”, Lima, Cofropi-PDPU. 
Field, Erica (2002), "Entitled to Work: Urban Property Rights and Labor Supply in Peru", Princeton Law and Public Affairs, octubre (Working Paper, 2).

Field, Erica (2005), "Property Rights and Investment in Urban Slums", Journal of the European Economic Association, vol. 3, pp. 279-290.

Field, Erica y Máximo Torero (2004), "Do Property Titles Increase Credit Access among the Urban Poor? Evidence from a Nationwide Titling Program”, Documento de Trabajo, Cambridge, Harvard University.

Gilbert, Alan (2001), On the Mystery of Capital and the Myths of Hernando de Soto: What Difference Does Legal Title Make?, Lovaina, NAERUS.

Gundermann K., Hans (2004), "El método de los estudios de casos”, en María Luisa Tarrés (coord.), Observar, escuchar y comprender. Sobre la tradición cualitativa en la investigación social, México, Porrúa/Flacso.

ILD (Instituto Libertad y Democracia) (2007), La guerra de los notarios, Lima, ILD.

ILD (Instituto Libertad y Democracia) (2004), "Trabas notariales niegan libre comercio e integración de los pobres", nota de prensa, Lima, diciembre.

Kagawa, Ayako (2000), Measuring the Measure: the Effects of Land Tenure Regularization Policy in Peru, Enschede, ITC.

Mitchell, Timothy (2006), "The Works of Economics: How a Discipline Make its World”, European Journal of Sociology, vol. 45, núm. 2, pp. 297-320.

Morris, Felipe, Víctor Endo y Rafael Ugaz (2005), Develando el misterio. La formalización de la propiedad en el Perú, Lima, Cofopri/Banco Mundial.

Mosqueira, Edgardo (2000), "Las reformas institucionales para la creación de un sistema de derechos de la propiedad", en Roberto Abusada, Fritz Du Bois, Eduardo Horón y José Valderrama (coords.), La reforma incompleta, Lima, Universidad del Pacífico/Instituto Peruano de Economía.

Parias, Adriana (2006), "Mercados informales de suelo y movilidad de los pobres en América Latina. El caso de Bogotá”, taller Mercados de Suelo en Asentamientos Informales en América Latina, Panamá, 18 a 20 de septiembre.

Path to Property (1997), La formalización de la propiedad: la solución Proform, Lima, Path to Property.

Payne, G, A. Durand Lasserve y C. Rakodi (2007), "Social and Economic Impacts of Land Titling Programmes in Urban and Peri-Urban Sreas: a Review of the Literature”, World Bank Urban Research Symposium, Washington, 14 a 16 de mayo.

Ramírez Corzo Daniel y Gustavo Riofrío (2006), Formalización de la propiedad y mejoramiento de barrios: bien legal, bien marginal, Lima, Estudios Urbanos/ Desco.

Ramírez, R., J. Fiori, H. Harms y K. Mathey (1992), "The Commodification of Self Help Housing and State Intervention”, en Kosta Mathey (coord.), Beyond Self Help Housing, Londres, Mansell. 
Smolka, Martim (2003), "Regularizacao da ocupacao do solo urbano. A solucao que é parte do problema, o problema que é parte da solucao", en P. Abramo (coord.), A ciudade da informalidade, Río de Janeiro, Sette Letras/ LILP.

Soto, Hernando de (1986), El otro sendero, Lima, ILD.

Soto, Hernando de (2000), El misterio del capital. Por qué el capitalismo triunfa en Occidente y fracasa en el resto del mundo, Lima, El Comercio.

Varela, David (2008), "Formalización de la propiedad predial en el Perú", Proyecto de Consolidación de los Derechos de Propiedad Inmueble, Seminario de Lanzamiento, Lima, 6 de marzo.

Villanes, José (2006), Análisis de los UCV de las partes altas de Huaycán, Lima, Curso Vivienda y Ciudad, Maestría en Arquitectura, Universidad Nacional de Ingeniería.

Webb, Richard, Diether Beuermann y Carla Revilla (2006), La construcción del derecho de propiedad. El caso de los asentamientos humanos en el Perú, Lima, Colegio de Notarios. 